\title{
Preliminary stages before nasal reconstruction using forehead flap: restoring perinasal subunits and nostril patency
}

\author{
Victor Diniz de Pochat ${ }^{1}$, Fernando César Câmara de Oliveira1, Felipe Simões da Rocha \\ Mata', Marcelo Sacramento Cunha', Nivaldo Alonso ${ }^{2}$, José Valber Lima Meneses ${ }^{1}$ \\ ${ }^{1}$ Division of Plastic Surgery, Federal University of Bahia, Salvador, Bahia 40110, Brazil. \\ ${ }^{2}$ Division of Plastic Surgery, University of São Paulo, São Paulo 14040, Brazil.
}

Address for correspondence: Dr. Victor Diniz de Pochat, Division of Plastic Surgery, University Hospital Professor Edgard Santos, Federal University of Bahia, Salvador, Bahia 40110, Brazil. E-mail: victor.pochat@gmail.com

\begin{abstract}
Due to the complex three-dimensional structure of the nose, the repair of the nasal defect requires reconstruction of three different layers: skin envelope, osteocartilaginous framework and nasal lining. Before nasal reconstruction can be accomplished, the nose must rest on a stable platform to avoid late nasal obstructions, and septal deviations resulting from scar contraction. We present three cases of nasal reconstruction using a forehead flap in which we performed a preliminary stage to increase reliability of outcomes.
\end{abstract}

Key words:

Forehead flap, nasal reconstruction, nostril stenosis, preliminary stages

\section{INTRODUCTION}

Reconstruction of the nose is complex, due to its three dimensionality, and its prominence in the central facial region. ${ }^{[1,2]}$ Full thickness nasal defects require repair of three different layers: skin envelope, osteocartilaginous framework and nasal lining. The latter one is considered the most challenging. ${ }^{[3,4]}$

Often, nasal defects extend into adjacent regions of the face such as the lips and cheeks, increasing the complexity of wound reconstruction. One can choose to simply "fill the hole"; however, when planning nasal reconstruction, the surgeon should be aware that the defect may not reflect the actual tissue loss. Swelling, infiltration of anesthesia, the action of gravity on tissues and scar retraction may alter the dimensions of the defect; and

\begin{tabular}{|l|l|}
\hline \multicolumn{2}{|c|}{ Access this article online } \\
\hline Quick Response Code: & Website: \\
\hline & www.parjournal.net \\
\cline { 1 - 2 } & \\
\hline & DOI: \\
\hline
\end{tabular}

therefore, may not reflect the true defect at the time of presentation. ${ }^{[5]}$

The nose rests on a platform consisting of the premaxilla and the piriform aperture surrounded by the adjacent soft tissues (upper lip and cheek) with a well-defined angle and location. Improper positioning of nasal structures, even for a few millimeters can generate significant distortions. If such a platform is unstable, it can displace the reconstructed alar region inferiorly or laterally over time. Preliminary procedures, such as the repair of the lip and cheek defects using local flaps and skin grafts flap are usually necessary to prevent distortions and scar contracture of the adjacent nose before nasal reconstruction. ${ }^{[6,7]}$

There is limited information about preliminary stages before paramedian forehead flap discussed in the literature. The aim of this study is to demonstrate the experience of the Rhinology team of the Plastic Surgery Department (HUPES-UFBA) using a preliminary stage to stabilize the nasal platform before nasal reconstruction using the paramedian forehead flap.

Between May 2011 and May 2013, the department of Plastic Surgery, HUPES-UFBA, performed 12 nasal reconstruction surgeries that required paramedian 
forehead flaps. Of these, 3 patients required preliminary procedures to stabilize the nasal platform.

The selected cases were reported, highlighting the indication and the technique used in the reconstruction in the donor area of the flap as well as in the nasal and perinasal region. The patients involved in this article agreed to publish their facial pictures and signed the consent form.

\section{CASE REPORT}

\section{Case I}

A 29-year-old man presented with a nasal deformity caused by paracoccidioidomycosis, which affected the right ala leading to the nostril stenosis. In a preliminary stage, the right nostril was opened with a Z-plasty and skin grafting was performed [Figure 1]. After 4 months, he underwent resection of the scarred area to construct the original defect using a three stage paramedian folded forehead flaps to resurface the lining and nasal subunits [Figure 2]. The cartilaginous support was achieved by a conchal cartilage graft performed in the second stage.

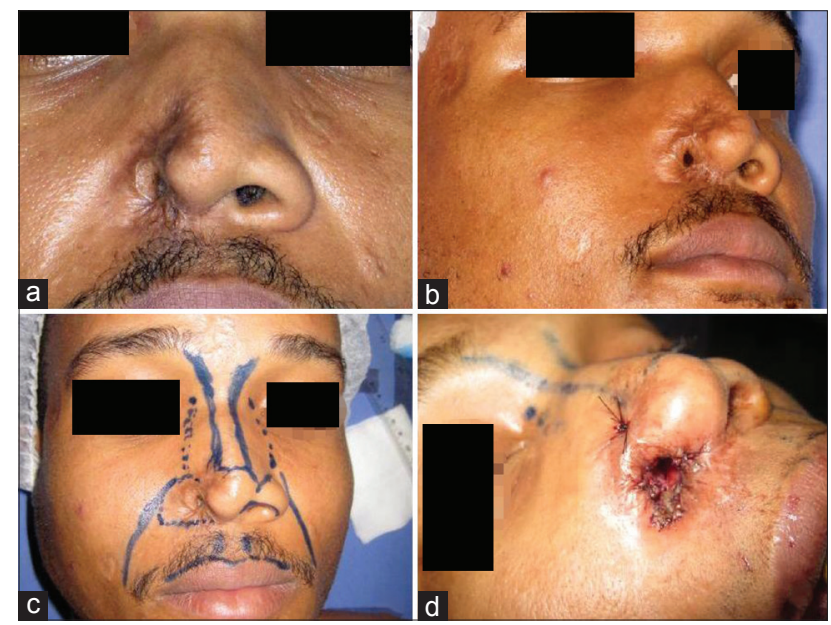

Figure 1: Case 1. Right ala destruction and nostril stenosis. (a) Fronta view, (b) oblique view, (c) preoperative landmark of aesthetic subunits, (d) immediate postoperative correction of the stenosis with Z-plasty and skin grafting

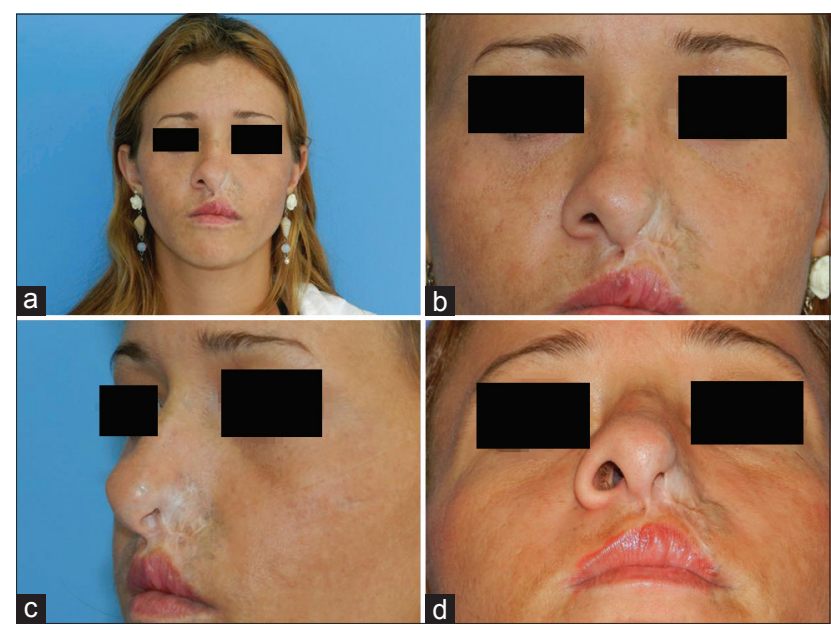

Figure 3: Case 2. Preoperative: (a) frontal view, (b) close up of frontal view showing upper lip retraction and deformity of left ala, (c) oblique view, (d) basal view

\section{Case 2}

A 26-year-old female, presented with a total loss of the left ala and upper lip retraction after a motorcycle accident 4 years prior [Figure 3]. A preliminary stage was indicated, and a Z-plasty with a full thickness skin graft was performed in order to fill the resulting gap. Furthermore, a nostril enlargement was performed using local flaps, and a tissue expander was placed in the forehead [Figure 4]. After 3 months, the expander was removed, and a paramedian forehead flap was transferred in two stages [Figure 5]. In addition, part of the left nostril scar was used as a hinge-over flap to resurface the missing nasal lining. The cartilaginous framework was rebuilt using a conchal graft.

\section{Case 3}

A 26-year-old man was referred to our department after an unsuccessful attempt at nasal reconstruction using a nasolabial flap. He sustained a gunshot trauma 8 years prior to presentation. In the preliminary stage, a costal cartilage graft was used for nasal dorsum augmentation. An advanced V-Y nasolabial flap was performed using the previous scar to fill the nasal base lining and a full thickness skin graft was placed to resurface nasal lining and unblock the left nostril. Three months later a three stage folded paramedian forehead flap was performed. In this case, a new forehead flap was required to allow better projection and support for the tip and resurfacing the columella [Figure 6].

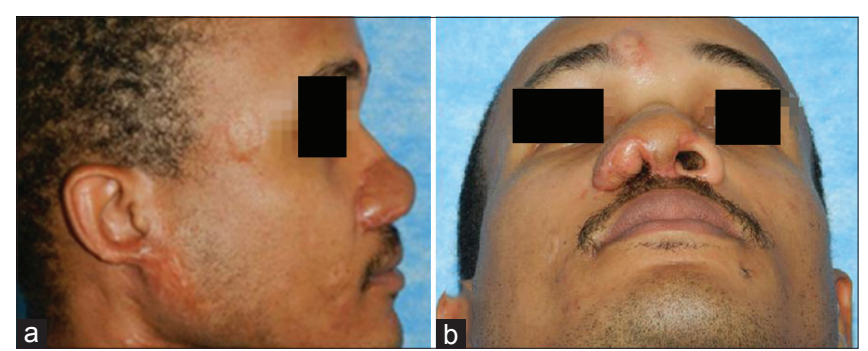

Figure 2: Case 1. One-month after the three-stage forehead flap. (a) Oblique view, (b) basal view

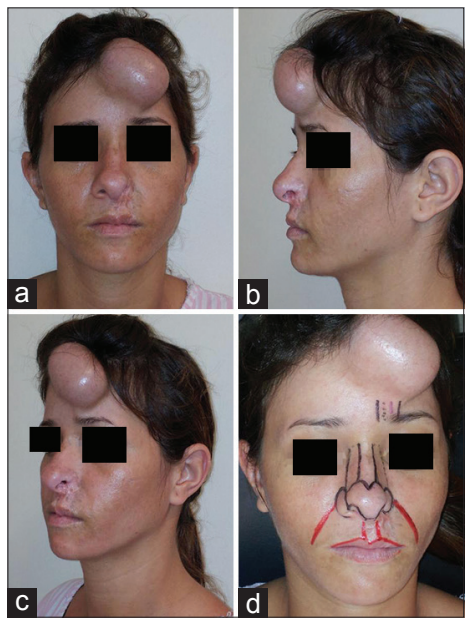

Figure 4: Case 2. Postoperative view after a preliminary stage including expansion of the forehead, correction of retraction of the upper lip and left nostril opening. (a) Frontal view, (b) lateral view, (c) oblique view, (d) frontal view with the landmarks 


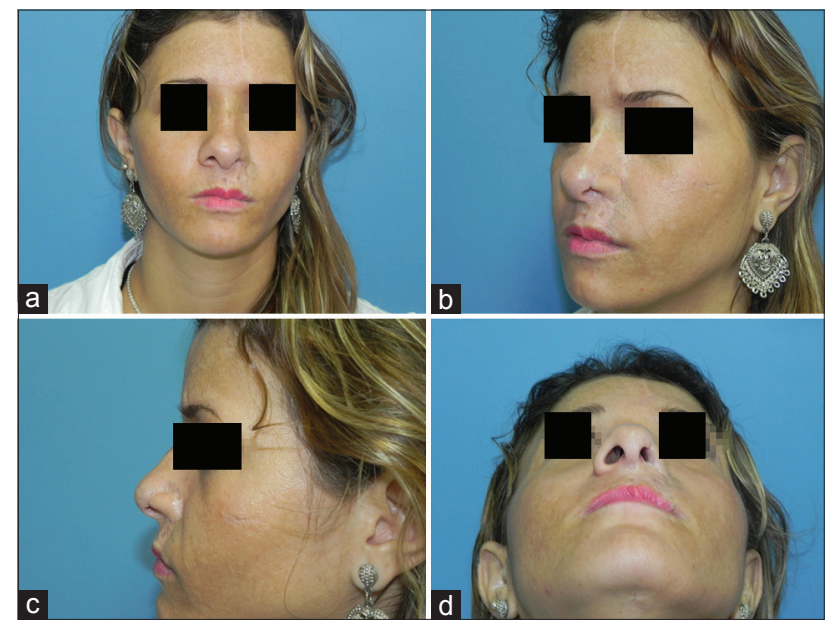

Figure 5: Case 2. Postoperative (4 months) after the expanded forehead flaps in two stages. (a) Frontal view, (b) oblique view, (c) lateral view, (d) base view

\section{DISCUSSION}

Scar contraction is a natural phenomenon in the healing process and is often not considered when planning surgical reconstruction. It is undesirable in nasal reconstruction, because minor flaws in preoperative plan can produce large distortions. The nose rests on a platform comprised of the premaxilla and the piriform aperture surrounded by the upper lip and cheek. This platform needs to be stable before planning a nasal reconstruction. In case 2, the lip position was corrected by releasing the retraction through a Z-plasty and skin grafting in the first stage. The forehead skin is the best donor site for nasal reconstruction because its color and texture are similar to the skin of the nose. It can be used for skin cover and lining repair. ${ }^{[8-11]}$ The donor site is only partially closed after the flap transfer, and it is allowed to heal by secondary intention.

In addition, after preliminary reconstruction of affected areas, tissue expanders can be used in the donor site before nasal reconstruction using forehead flap. Some authors suggested the use of expanders in the forehead to improve scarring in the donor area and to provide large surface area to cover large defects. ${ }^{[9]}$ In our department, scar improvement is not an indication for a saline expander. In patients with shortened vertical forehead height, the inclusion of scalp skin in the flap is not recommended due to the difference of texture and color of the nasal skin. ${ }^{[10]}$ In such cases, we consider the use of expanders as a primary indication prior to forehead flap. The expanded flap has the advantage of decreased thickness that allows accurate reconstruction in two stages. Thus, the three stages reconstruction is restricted to more complex cases that require lining repair.

The airway patency is restored by excising the scar tissue and releasing retraction. Remaining excess tissue can be used as a flap to increase the nasal lining or to open the airway instead of being discarded. The nose should be rebuilt in a late stage following the principle

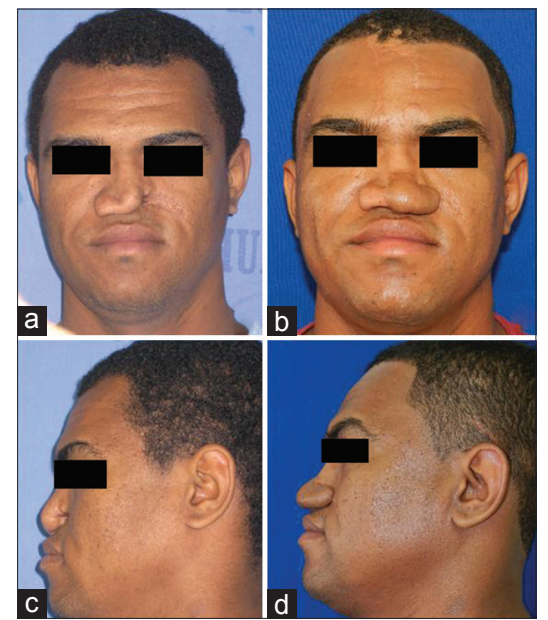

Figure 6: Case 3. Preoperative. (a) Frontal view, (c) lateral view. Postoperative ( 8 months) after the last procedure (three-stage forehead flap). (b) frontal view, (d) lateral view

of the subunits when the adjacent soft tissue structures are stable. In preliminary stages, scar tissue should be thoroughly evaluated in order to recreate the defect and be used as local flaps for lining repair (hinge-over flaps or V-Y flaps) or to widen the nostril (Z-plasty and skin grafts) as performed in cases 1 and 2 .

Restoration of nasal lining requires replacement of a well-vascularized, thin and supple tissue that supports cartilage grafts. It should provide an ideal shape while preventing nasal stenosis. Nasal lining can be reconstructed by advancing the residual lining, hinge-over lining flaps, and skin grafts. Lining can also be replaced by intranasal lining flaps, folded forehead flaps, nasolabial flaps, prefabricated forehead flaps and free flaps.

Any procedure performed on the nose produces the fibrosis that makes any subsequent manipulation difficult. In our study, the nostril expansion was performed in a preliminary because after a two or three stage forehead flap, one will find more fibrosis (mainly after muscle excision) that would render the thinning the alar margins more difficult and may decrease reliability of the vascularization of the small local flaps. Menick ${ }^{[5 \mid}$ suggested using templates based on the contralateral normal ala. Thus, the adjacent nostril floor must be re-established and stabilized prior to nasal reconstruction.

In conclusion, correction of perinasal defects and the nostril stenosis should be performed as a preliminary stage to allow stabilization of the healing process. Any scar resection must be well-planned, since this tissue may be useful as hinge-over flaps for lining or as local flap for nasal stenosis correction.

\section{REFERENCES}

I. Taghinia $\mathrm{AH}$, Pribaz J]. Complex nasal reconstruction. Plast Reconstr Surg 2008; I 2 I:el5-27.

2. de Pochat VD, Alonso N, Figueredo A, Ribeiro EB, Mendes RR, Meneses JV. The role of septal cartilage in rhinoplasty: cadaveric analysis and assessment of graft selection. Aesthet Surg J 201 I;31:891-6.

3. Murakami CS, Kriet JD, lerokomos AP.Nasal reconstruction using the inferior turbinate mucosal flap. Arch Facial Plast Surg 1999;1:97-100. 
4. Sedwick JD, Graham V, Tolan CJ, Sykes JM, Terkonda RP. The full-thickness forehead flap for complex nasal defects: a preliminary study. Otolaryngol Head Neck Surg 2005; I32:38I-6.

5. Menick FJ. Defects of the nose, lip, and cheek: rebuilding the composite defect. Plast Reconstr Surg 2007; 120:887-98.

6. Menick FJ. Nasal reconstruction. Plast Reconstr Surg 20 I 0; I25:e I 38-50.

7. Menick FJ. Practical details of nasal reconstruction. Plast Reconstr Surg 2013;131:e613-30.

8. Alagöz MS, Isken T, Sen C, Onyedi M, Izmirli H, Yücel E. Three dimensional nasal reconstruction using a prefabricated forehead flap: case report. Aesthetic Plast Surg 2008;32:166-7I.

9. Menick FJ.A I0-year experience in nasal reconstruction with the three-stage forehead flap. Plast Reconstr Surg 2002; 109:1839-55.

10. Weng R, Li Q, Gu B, Liu K, Shen G, Xie F. Extended forehead skin expansion and single-stage nasal subunit plasty for nasal reconstruction. Plast Reconstr Surg 2010;125:1।119-28.

II. Wang ZG, Chen XJ, Chen ZY.A modified bilobed flap design for nasal tip defects. Plast Aesthetic Res 2014;1:16-20.

How to cite this article: de Pochat VD, de Oliveira FCC, da Rocha Mata FS, Cunha MS, Alonso N, Meneses JVL. Preliminary stages before nasal reconstruction using forehead flap: restoring perinasal subunits and nostril patency. Plast Aesthet Res 2015;2:34-7. Source of Support: Nil, Conflict of Interest: None declared.

Received: 21-07-2014; Accepted: 08-10-2014 